\title{
Labyrinthe
}

4 | 1999

Numéro 4

Mise en perspective

\section{L'histoire médiévale et la « nouvelle érudition »}

L'exemple de la diplomatique

\section{Yann Potin et Julien Théry}

\section{QpenEdition}

\section{Journals}

Édition électronique

URL : http://journals.openedition.org/labyrinthe/118

DOI : 10.4000/labyrinthe.118

ISSN : 1950-6031

Éditeur

Hermann

Édition imprimée

Date de publication : 1 octobre 1999

Pagination : 35-39

Référence électronique

Yann Potin et Julien Théry, «L'histoire médiévale et la « nouvelle érudition » », Labyrinthe [En ligne], 4 | 1999, mis en ligne le 15 février 2005, consulté le 21 septembre 2020. URL : http://

journals.openedition.org/labyrinthe/118; DOI : https://doi.org/10.4000/labyrinthe.118

Ce document a été généré automatiquement le 21 septembre 2020

Propriété intellectuelle 


\title{
L'histoire médiévale et la « nouvelle érudition »
}

\author{
L'exemple de la diplomatique
}

Yann Potin et Julien Théry

1 L'analyse critique des documents, avec toutes ses exigences techniques et érudites, se trouve désormais, d'une manière assumée, au cœur du travail interprétatif de l'historien. L'article de Sébastien Barret offre une bonne illustration de cette «nouvelle érudition ", qui n'a rien d'un retour pénitentiel au primat du document sur l'interprétation historique. Elle entérine au contraire la dissolution de ce vieux clivage, aujourd'hui dénué d'une grande partie de son sens. Au moment où les disciplines érudites développent une approche des formes documentaires non moins technique, mais plus historique et interprétative, la «nouvelle érudition » est avant tout fusion, ou indistinction, entre histoire-source et histoire-problème. N'est-ce pas là une condition nécessaire à l'histoire totale?

2 Le lourd passé des relations entre histoire et disciplines érudites pourrait masquer l'originalité du renouveau, bien éloigné d'un quelconque revival positiviste. Dans les dernières décennies du XIXe siècle, c'est en mettant à son service les disciplines érudites naissantes que l'histoire a fondé sa scientificité. Combinant les méthodes de la philologie, de la diplomatique, de la paléographie ou encore de l'héraldique et de la sigillographie, l'historien présidait à l'établissement des faits en une sorte de gouvernement souverain exercé sur ces « sciences auxiliaires ». À partir de la formation de l'école des Annales, la rupture avec cette « vieille histoire » et l'aspiration aux analyses totales d'une histoire interprétative s'accompagnèrent d'un rejet affiché, parfois violent et méprisant, de l'érudition critique, assimilée tout entière au dessèchement de l'historiographie positiviste. La " nouvelle érudition » dépasse le double malentendu qui a nourri, pendant un demi-siècle au moins, ce mouvement de réaction. Car les recherches historiques ne cessèrent jamais en réalité, après l'âge positiviste, de se fonder sur des travaux d'érudition considérables, bien que moins mis en valeur. Les méthodes de l'érudition critique, quant à elles, n'étaient en rien 
consubstantiellement liées à une approche bornée aux « faits » dans l'acception étroite qui fut celle du positivisme dominant.

3 L'histoire est autre chose qu'une simple application aux mondes passés des concepts propres aux sciences sociales, et cette spécificité tient peut-être à un aspect particulier du travail de l'historien, partagé avec le spécialiste d'une discipline d'érudition critique : faire de l'histoire, c'est toujours commencer par restaurer une lisibilité. Nécessitant compétences techniques et érudites, la lisibilité des documents ouvre à celle des sociétés disparues dont ils constituent les traces. Mais dans cette restauration même s'élaborent les problématiques propres à l'analyse d'objets que l'épaisseur du temps nous a rendus étranges. La « nouvelle érudition » trouve sa nécessité dans ce constat.

4 Parmi les disciplines érudites qui constituent le socle de la méthode historique, les études diplomatiques, concernant la période médiévale essentiellement ${ }^{1}$, sont représentatives à bien des égards du renversement d'approche actuellement à l'œuvre. En témoigne l'article de Sébastien Barret, fondé sur l'étude d'un acte royal.

5 La diplomatique a d'abord servi à faire la guerre. Des guerres de privilèges et de titres au cours desquelles s'affrontaient plusieurs légitimités documentaires, ayant pour but l'obtention d'un statut social ou d'une reconnaissance juridique. Il s'agissait d'authentifier des documents, à partir d'une masse documentaire indistincte dans ses formes et ses usages, pour justifier des droits et des distinctions sociales. Les joutes érudites de l'âge moderne mettaient aux prises abbayes, villes et personnes privées, et furent précisément désignées par l'expression de bella diplomatica. Acte fondateur de la diplomatique en tant que science, la publication en 1681 du De re diplomatica par Dom Jean Mabillon s'inscrivait dans un conflit de ce type : en 1675, le jésuite Papenbroeck avait mis en doute l'authenticité des documents mérovingiens sur papyrus, les plus anciens textes médiévaux conservés pour l'Occident, détenus presque en totalité par le monastère de Saint-Denis. La légitimité ecclésiastique de l'abbaye et, audelà, les fondements politiques de la monarchie française étaient en cause. Hormis une contre-attaque ponctuelle, et qui fut efficace, le traité de Mabillon se proposait de fixer une méthode critique de référence. Il y avait là une sorte de convention de Genève des bella diplomatica ; mais à cette occasion étaient jetées les bases d'une nouvelle science.

6 La fin de l'Ancien Régime a fait perdre à la diplomatique son utilité juridique et l'a entraînée sur les terrains moins belliqueux de l'érudition historique, asservie par l'histoire positiviste. Les contenus et les limites des histoires événementielles nationales, qui structurent encore largement les horizons de la discipline historique actuelle, reposent sur une critique diplomatique systématique du patrimoine documentaire. Dans cette optique, la discipline s'est focalisée sur les procédés d'épuration des textes, en se fixant pour objectif principal l'élimination des gangues rhétoriques et stylistiques masquant les éléments « originaux » (c'est-à-dire les « faits ») contenus dans les documents. Si ce développement a permis la mise en place d'un vocabulaire, de concepts et de méthodes propres à la technique diplomatique (essentiellement critique des faux et typologie des actes), il a cantonné la discipline dans le cercle des sciences auxiliaires de l'histoire. Une inertie méthodologique s'est alors imposée, garantie par un impératif érudit d'accumulation factuelle et positive.

7 Le changement de perspective en cours est le produit d'une conjonction entre l'évolution méthodologique interne de la critique diplomatique et le contexte épistémologique de « révolution documentaire » dans les sciences humaines, décrite et 
initiée par Michel Foucault dans Les Mots et les choses et L'Archéologie du savoir puis recueillie par les historiens de la Nouvelle Histoire ${ }^{2}$. L'érudition allemande, notamment, a mis l'accent sur l'intérêt intrinsèque des faux documentaires ou des copies volontairement infidèles, en tant que révélateurs des « mentalités » et indices des préoccupations mémorielles des sociétés. Les diplomatistes ont également renouvelé l'approche des cartulaires, recueils de copies d'actes juridiques dont le manque de fiabilité sur les faits allégués ne suscite plus les déplorations de jadis, mais plutôt de nouvelles réflexions sur les fonctions commémoratives autant qu'administratives de ces documents. Ces nouvelles démarches, attentives au statut complexe de l'écrit, rejoignaient de façon inattendue les préoccupations d'une réflexion plus proprement philosophique sur la valeur des discours, qui culmine chez Foucault dans la perception des documents comme monuments, entre mémoire et représentation.

8 " C'est la forme même du document - procédures de composition, normes de présentation, formulaire - qui est à son tour devenue objet d'histoire ${ }^{3}$ ». Olivier Guyotjeannin, dans un article fondamental auquel ces réflexions doivent beaucoup, désigne ainsi les nouvelles voies de la discipline, vouée à produire de nouveaux matériaux et de "nouveaux territoires " pour l'historien. Deux angles complémentaires d'approche sont actuellement privilégiés. Les formes des documents, tant matérielles que lexicales ou rhétoriques, sont à l'origine d'un réexamen des fonctions et des statuts des documents eux-mêmes et donc de la représentativité des informations qu'ils recèlent. Les contenus textuels des actes juridiques permettent d'autre part, comme le montre l'article de Sébastien Barret, d'appréhender la densité des situations sociales et politiques qui se dissimulent derrière l'apparente banalité et la récurrence des discours administratifs.

\section{BIBLIOGRAPHIE}

DELMAS Bruno, «Manifeste pour une diplomatique contemporaine : des documents institutionnels à l'information organisée », Gazette des Archives, n 172, Paris, 1994, p. 49-70.

GRAFTON Antony, Faussaires et critiques. Créativité et duplicité chez les érudits occidentaux, Paris, Les Belles Lettres, 1993 (éd. originale, Princeton, 1990).

GUYOTJEANNIN Olivier, « La diplomatique médiévale et l'élargissement de son champ », Gazette des Archives, $\mathrm{n}^{\circ}$ 172, Paris, 1994, p. 12-18.

-, «L'érudition transfigurée ", dans Passés recomposés : champs et chantiers de l'histoire, sous la direction de Jean Boutier et de Dominique Julia, Paris, Autrement, 1995, p. 152-162.

GUYOTJEANNIN Olivier, PYCKE Jacques et TOcK Benoît-Michel, Diplomatique médiévale, Turnhout, Brepols, 1993.

LE GOFF Jacques, « Documento/monumento », dans Enciclopedia Einaudi, t. V, Turin, 1978, p. 38-48. 
"Sciences auxiliaires de l'histoire médiévale », L'Histoire médiévale en France : bilan et perspectives, textes réunis par Michel Balard, Paris, Le Seuil, 1991, p. 471-499.

TESSIER Georges, « Diplomatique », dans L'Histoire et ses méthodes. Encyclopédie de la Pléiade, sous la direction de Charles Samaran, Paris, Gallimard, 1961, p. 633-675.

TOUBERT Pierre, « Tout est document », dans L'Ogre historien. Autour de Jacques Le Goff, textes rassemblés par Jacques Revel et Jean-Claude Schmitt, Paris, Gallimard, 1998, p. 85-105.

\section{NOTES}

1.Une extension des méthodes et des problématiques aux périodes contemporaines est en cours : voir à ce sujet Bruno Delmas, « Manifeste pour une diplomatique contemporaine : des documents institutionnels à l'information organisée », Gazette des Archives, n $^{\circ} 172$, Paris, 1994, p. 49-70.

2.Voir notamment Jacques Le Goff, « Documento/monumento », dans Enciclopedia Einaudi, t. V, Turin, 1978, p. 38-48 ; ainsi que la synthèse récente de Pierre Toubert, « Tout est document ", dans L'Ogre historien. Autour de Jacques Le Goff, textes rassemblés par Jacques Revel et Jean-Claude Schmitt, Paris, Gallimard, 1998, p. 85-105.

3. «L'érudition transfigurée », dans Passés recomposés : champs et chantiers de l'histoire, sous la direction de Jean Boutier et de Dominique Julia, Paris, Autrement, 1995, p. 152-162, ici p. 157.

\section{AUTEURS}

\section{JULIEN THÉRY}

Yann Potin est élève de l'École normale supérieure de Fontenay/Saint-Cloud. 